\title{
Comportamento ingestivo de vacas mestiças alimentadas com diferentes volumosos
}

\section{Ingestive behavior of crossbred cows fed with different forages}

\author{
Susi Cristina dos Santos Guimarães Martins, ${ }^{*}$ Vicente Ribeiro Rocha Júnior, ${ }^{*}$ Luciana Albuquerque Caldeira, ${ }^{*}$ \\ Isabella Coutinho Barros, ${ }^{*}$ Geanderson Walder Vieira da Silva, ${ }^{*}$ Maria Dulcinéia da Costa, ${ }^{*}$ \\ Malber Natham Nobre Palma, ${ }^{*}$ André Santos de Souza**
}

\begin{abstract}
Resumo
Objetivou-se avaliar o comportamento ingestivo de vacas mestiças em lactação submetidas a dietas, formuladas para um mesmo nível de produção de leite, com diferentes volumosos (cana-de-açúcar, silagem de sorgo, silagem de girassol e pasto de capimtanzânia). Foram utilizados dois quadrados latinos $4 \times 4$, cada um composto de quatro animais, quatro dietas e quatro períodos experimentais. As vacas foram submetidas à observação visual para avaliação do comportamento ingestivo. $O$ maior tempo de alimentação foi para a dieta com pasto e o menor tempo de ruminação e maior tempo de ócio para a dieta com silagem de girassol. O tempo despendido para o consumo de matéria seca foi maior para a dieta com pasto de capim-tanzânia e para o consumo de fibra em detergente neutro foi menor para a dieta com silagem de sorgo. A eficiência de alimentação da matéria seca foi pior para a dieta com pasto de capim-tanzânia. Entretanto, para eficiência de alimentação da FDN, as dietas com pasto de capim-tanzânia e silagem de sorgo mostraram-se superiores. As dietas com silagem de girassol e cana proporcionaram maior eficiência de alimentação da matéria seca e menor eficiência da alimentação e ruminação da FDN. Dietas com diferentes volumosos alteraram o comportamento ingestivo de vacas mestiças em lactação.
\end{abstract}

Palavras-chave: bovinos, etologia, mastigação, ócio, ruminação.

\begin{abstract}
The objective was to evaluate the ingestive behavior of lactating crossbred cows fed diet formulated to the same level of milk production with different forages (sugarcane silage, sorghum silage, sunflower silage and Tanzania grass pasture). Two Latin Squares $4 \times 4$ were used, each consisting of four animals, four diets and four experimental periods. Cows were subjected to visual observation for assessment of ingestive behavior. The longer food was for the grass diet, less time at ruminating and longer leisure for the sunflower silage diet. The spent time for dry matter intake was higher for Tanzania grass pasture, and for the consumption of neutral detergent fiber was lower for the sorghum silage diet. The feeding efficiency of dry matter was worse for the Tanzania grass diet. Feed efficiency of neutral detergent fiber was better for the Tanzania grass and silage sorghum diet. The sunflower and sugar-cane silage diets provided the highest efficiency of dry matter and lowest feeding and rumination efficiency of neutral detergent fiber. Diets with different forage altered the feeding behavior of lactating crossbred cows.
\end{abstract}

Keywords: bovines, chewing, ethology, leisure, ruminating.

\section{Introdução}

$O$ gado leiteiro pode modificar o comportamento ingestivo de acordo com o tipo, a quantidade e acessibilidade do alimento e às práticas de manejo (Olivo et al., 2008; Oliveira et al., 2011). O tempo de ruminação pode aumentar em função de um maior consumo de alimento contendo elevada proporção de constituintes fibrosos (Carvalho et al., 2004; Pereira et al., 2007; Barros et al., 2011). A alimentação contendo alto teor de fibra em detergente neutro (FDN) promove redução no consumo de matéria seca total, devido à limitação provocada pela repleção do rúmen-retículo (Van Soest, 1994).
Experimentos citados por Sousa et al. (2009), em que compararam forragens com diferentes digestibilidades da fibra em detergente neutro, mas com teores de FDN e de proteína semelhantes, para vacas leiteiras em lactação, constataram aumentos significativos na ingestão de matéria seca e produção de leite, quando a digestibilidade da FDN foi maior.

Por outro lado, a ingestão de alimentos também é influenciada pela concentração energética da dieta. Em concentrações energéticas mais elevadas, o centro da saciedade do animal é estimulado com um menor consumo de matéria seca (Gonçalves et al., 2001; Carvalho et al., 2008).

\footnotetext{
* Departamento de Ciências Agrárias / Zootecnia / UNIMONTES.

" Departamento de Zootecnia / Escola de Veterinária da UFMG.

Autor para correspondência: E-mail: vicente.rocha@unimontes.br. Av. Reinaldo Viana 2630, Bico da Pedra, Campus Universitário, Janaúba/MG, CEP.39440-000.
} 
O estudo do comportamento ingestivo das vacas mestiças em lactação alimentadas com os volumosos avaliados neste trabalho foi importante para a compreensão dos fatores que estão relacionados com a ingestão destes alimentos, pois de acordo com Van Soest (1994), o desempenho animal está em função do consumo de matéria seca digestível.

Objetivou-se com o desenvolvimento deste trabalho avaliar o comportamento ingestivo de vacas mestiças em lactação submetidas a dietas, formuladas para um mesmo nível de produção de leite, com diferentes volumosos, no Norte de Minas Gerais.

\section{Material e métodos}

O experimento foi realizado no Instituto Federal do Norte de Minas Gerais - Campus Salinas. Salinas está situada no Norte de Minas Gerais e apresenta baixo índice de pluviosidade, com uma média anual em torno de $700 \mathrm{~mm}$ de chuvas. O solo, em geral é bastante acidentado e de baixa fertilidade natural. Segundo a classificação de Koppen, o tipo de clima predominante na área em estudo é o Aw, caracterizado pela existência de uma estação seca bem acentuada no inverno, e a temperatura média do mês mais frio é superior a $18^{\circ} \mathrm{C}$ (Epamig, 1994). No período experimental, a temperatura média foi de $21,6^{\circ} \mathrm{C}$, a pluviosidade de $175,4 \mathrm{~mm}$ e a umidade relativa média do ar de $78,9 \%$.

Foram utilizadas oito vacas mestiças $1 / 2$ sangue Holandês/ Gir, com período de lactação de $180 \pm 12$ dias. Utilizaram-se quatro dietas experimentais, uma para cada um dos volumosos estudados (cana-de-açúcar, silagem de girassol, silagem de sorgo e pasto de Panicum maximum cv. Tanzânia). As dietas foram formuladas conforme descrito pelo NRC (2001) para atender a exigência de produção de $20 \mathrm{~kg}$ de leite/dia com $4 \%$ de gordura e foram formuladas para serem isoprotéicas (Tabela 1). $O$ experimento teve duração de 72 dias, sendo dividido em quatro períodos de 18 dias, os 15 primeiros dias de cada período foram destinados à adaptação dos animais às dietas, e os três últimos dias para coleta de dados, segundo metodologia descrita por Santos et al. (2006). O delineamento experimental adotado foi: quadrados latinos $4 \times 4$ compostos, cada um, de quatro animais, quatro tratamentos e quatro períodos experimentais.

O sorgo utilizado para produção da silagem foi o IPA 70301011 e a ensilagem foi realizada quando os grãos da panícula se apresentavam na fase de pastoso a farináceo. O girassol utilizado foi o híbrido 251, utilizando-se uma densidade de plantio de 50.000 plantas/ha, e o girassol foi ensilado com 95 dias após o plantio, quando apresentava as folhas e as brácteas com coloração parda e o capítulo caído. A cana-de-açúcar utilizada no experimento foi a variedade SP 79-1011.

A pastagem de Panicum maximum cv. Tanzânia foi implantada há mais de seis anos. Foi feita uma adubação nitrogenada com $100 \mathrm{~kg} / \mathrm{ha}$ distribuídos em duas parcelas. A pastagem foi manejada para se obter altura de resíduo em torno de $40-45 \mathrm{~cm}$, com massa de forragem pós-pastejo em torno de 2500 a 3000 $\mathrm{kg}$ de MS/ha. A disponibilidade de forragem foi obtida por meio da coleta de amostras de pasto utilizando-se um quadrado com área conhecida (Gardner, 1986). Com base nesses parâmetros, procedeu-se ao dimensionamento dos piquetes. Cada vaca ficou em piquetes separados e o período de pastejo foi de três dias. Quando necessário, foram utilizados animais reguladores conforme técnica de put and take, descrita por Mott e Lucas (1952).

Seis vacas foram mantidas em baias individuais de $20 \mathrm{~m}^{2} \mathrm{com}$ parte do piso cimentado e parte de terra, separadas por cerca de arame liso com área coberta de $6 \mathrm{~m}^{2}$, dotadas de cochos e bebedouros. As duas vacas que receberam tratamento à base de pastagem de Panicum maximum cv. Tanzânia ficavam em piquetes, uma vaca em cada piquete, separados com cerca elétrica dotados de bebedouro e cocho com mineral. As vacas foram ordenhadas com ordenhadeira mecânica duas vezes ao dia, às $7 \mathrm{~h} 30$ e às $15 \mathrm{~h} 30$.

As dietas, para os animais em confinamento, foram fornecidas duas vezes por dia: às $8 \mathrm{~h}$ e às $16 \mathrm{~h}$. Os volumosos (cana-de açúcar picada, silagem de sorgo e silagem de girassol) de cada tratamento foram pesados em balança digital colocados nos respectivos cochos e misturados com parte do concentrado. $A$ outra parte do concentrado foi fornecida na hora da ordenha. As sobras do cocho foram pesadas e registradas, e as dietas foram ajustadas de acordo com as sobras, mantendo a relação volumoso:concentrado com base na MS (Tabela 1), de forma que as sobras representassem $10 \%$ da quantidade fornecida. $O$ consumo foi determinado subtraindo-se da quantidade fornecida as sobras do cocho.

As vacas que estavam em sistema de pastejo receberam todo o concentrado no momento da ordenha (manhã e tarde). Para a estimativa do consumo, utilizou-se a fibra em detergente ácido indigestível (FDAi) como indicador interno (Cochran et al.,1986), adotando-se como tempo de incubação in situ, 264 horas, de acordo com recomendação de Casali et al. (2008), sendo o consumo de MS (CMS) dado pela equação (Detmann et al., 2001): CMS (kg/dia) $=\{[(E F x C I F)-I S] / C I F O\}+C M S S$, em que: $\mathrm{CIF}=$ concentração do indicador nas fezes; CIFO = concentração do indicador na forragem; CMSS = consumo de matéria seca de suplemento concentrado (kg/dia); EF = excreção fecal (kg/dia); e IS = indicador presente no suplemento concentrado ( $\mathrm{kg} / \mathrm{dia})$.

Nos últimos três dias de cada período, amostras dos alimentos fornecidos, das sobras e das fezes foram recolhidas diariamente pela manhã e armazenadas em freezer.

A cada ciclo de pastejo, antes da entrada dos animais nos piquetes, foi realizada a coleta da forragem consumida para determinação da composição química. Para isso, utilizou-se a técnica do pastejo simulado (hand-plucked), coletando a forragem manualmente em pontos representativos do piquete (Johnson, 1978). Observou-se o comportamento de pastejo dos animais e a altura do resíduo dos piquetes adjacentes recémpastejados. Do material colhido em cada ponto do piquete, formou-se uma amostra composta para análises laboratoriais.

No final do experimento, foi feita uma amostra composta por animal e por período, sendo pré-seca em estufa de ventilação forçada a $55^{\circ} \mathrm{C}$ até que atingisse peso constante. Posteriormente, todas as amostras foram moídas em moinho de facas com peneira de malha com crivos de $1 \mathrm{~mm}$ de diâmetro, para análises laboratoriais; uma parte da amostra foi moída em peneira com crivos de $5 \mathrm{~mm}$ de diâmetro, para incubação ruminal. A composição química e bromatológica dos alimentos, das fezes e das sobras foram determinadas. As análises de matéria seca, proteína bruta, lignina, extrato etéreo, matéria orgânica e cinzas foram realizadas conforme procedimentos descritos pela AOAC 
(1990). A fibra em detergente neutro e a fibra em detergente ácido foram determinadas seguindo as recomendações de Van Soest et al. (1991), assim como os teores de compostos nitrogenados insolúveis em detergente neutro (NIDN) e em detergente ácido (NIDA), sendo a fibra em detergente neutro dos alimentos corrigida para proteína. Os carboidratos totais (CHOT) foram calculados segundo metodologia descrita por Sniffen et al. (1992). Os carboidratos não fibrosos (CNF) foram obtidos subtraindo-se dos CHOT a fração FDN. O NDT dos alimentos foi calculado conforme o NRC (2001), de acordo com a seguinte equação: NDT $=$ PBD + 2,25AGD + FDNpD + CNFD - 7; onde o valor 7 se refere ao NDT fecal metabólico. As análises foram realizadas no Laboratório de Análise de Alimentos do Departamento de Ciências Agrárias da UNIMONTES. Na Tabela 1 é apresentada a composição das dietas experimentais.

Tabela 1: Proporção de ingredientes e composição bromatológica e NDT das dietas, na base da matéria seca

\begin{tabular}{|c|c|c|c|c|}
\hline \multicolumn{5}{|c|}{ Composição dos ingredientes (\% MS) } \\
\hline Item & $\begin{array}{l}\text { Cana-de- } \\
\text { açúcar }\end{array}$ & $\begin{array}{l}\text { Silagem de } \\
\text { Sorgo }\end{array}$ & $\begin{array}{c}\text { Silagem de } \\
\text { Girassol }\end{array}$ & $\begin{array}{l}\text { Capim- } \\
\text { Tanzânia }\end{array}$ \\
\hline Cana-de-açúcar & 49,60 & - & - & - \\
\hline Silagem de Sorgo & - & 76,67 & - & - \\
\hline Silagem de Girassol & - & - & 59,37 & - \\
\hline Capim-Tanzânia & - & - & - & 75,77 \\
\hline Milho moído & 30,09 & 15,54 & 34,40 & 17,84 \\
\hline Farelo de soja & 17,41 & 5,62 & 4,60 & 4,40 \\
\hline Ureia/Sulfato de Amônio & 1,00 & 0,90 & 0,99 & 0,83 \\
\hline Suplemento Mineral & 1,90 & 1,27 & 0,64 & 1,16 \\
\hline Volumoso:Concentrado, \%MS & $50: 50$ & $77: 23$ & $60: 40$ & $76: 24$ \\
\hline \multicolumn{5}{|c|}{ Composição bromatológica, \% da MS } \\
\hline Matéria Seca & 56,67 & 42,13 & 49,70 & 37,79 \\
\hline Matéria Orgânica & 95,18 & 92,06 & 89,01 & 93,41 \\
\hline Proteína Bruta & 14,68 & 14,48 & 14,77 & 13,74 \\
\hline NIDN & 0,48 & 1,01 & 0,82 & 0,94 \\
\hline NIDA & 0,35 & 0,59 & 0,76 & 0,70 \\
\hline Extrato Etéreo & 5,60 & 5,31 & 7,54 & 5,97 \\
\hline Carboidratos Totais & 66,06 & 65,53 & 61,35 & 67,47 \\
\hline Carboidratos não fibrosos & 39,22 & 9,72 & 23,52 & 12,66 \\
\hline Fibra em detergente neutro & 35,08 & 62,53 & 43,27 & 60,65 \\
\hline FDNP & 32,02 & 56,24 & 38,16 & 54,81 \\
\hline Fibra em detergente ácido & 18,71 & 33,04 & 32,47 & 38,54 \\
\hline Lignina & 1,70 & 5,29 & 4,59 & 3,05 \\
\hline Nutrientes digestíveis totais & 67,79 & 64,24 & 66,75 & 62,79 \\
\hline
\end{tabular}

NIDN = nitrogênio insolúvel em detergente neutro; NIDA = nitrogênio insolúvel em detergente ácido; FDNP = Fibra em detergente Neutro corrigida para proteína.
Como as dietas foram formuladas para um mesmo nível de produção de leite, a relação volumoso:concentrado na base da matéria seca (Tabela 1) foi ajustada para cada tipo de volumoso, em função do nível de consumo de cada dieta.

A composição dos volumosos e dos ingredientes dos concentrados é apresentada na Tabela 2.

As oito vacas foram submetidas à observação visual para avaliação do comportamento ingestivo em dois dias consecutivos, no 16 e 17으 dia de cada período experimental. No primeiro dia, foram realizadas as contagens do número de mastigações merícicas e a determinação do tempo despendido na ruminação de cada bolo ruminal, para cada animal, com a utilização de um cronômetro digital. No dia subsequente, foi feita a observação visual de cada animal a cada 10 minutos (Burger et al., 2000), durante 24 horas, para determinação dos tempos despendidos com alimentação (TA), ruminação (TR) e ócio (TO) e dos números de períodos de alimentação (NPA), ruminação (NPR) e ócio (NPO). Os valores do tempo despendido e do número de mastigações merícicas por bolo ruminal foram obtidos a partir das observações feitas durante a ruminação de três bolos ruminais, em três períodos diferentes do dia, pela manhã, início e final da tarde.

Durante a observação noturna das vacas, o ambiente foi mantido com iluminação artificial. O número de mastigações merícicas em 24 horas foi obtido mediante a multiplicação do tempo médio de ruminação nas 24 horas do dia pelo número de mastigações merícicas por minuto. O número médio de bolos em 24 horas foi obtido através da divisão do tempo médio de ruminação, nas 24 horas do dia, com o tempo médio de mastigações por bolo. A partir desses dados foram calculados também a duração do período de alimentação (DPA), ruminação (DPR) e ócio (DPO) em minutos por período. O consumo de MS (CMS) e FDN (CFDN) em minutos por $\mathrm{kg}$ foi calculado dividindo-se o tempo de alimentação (em minutos) pelo consumo de matéria seca e FDN (em kg). Da mesma forma, estimou-se a ruminação da matéria seca (RMS) e da FDN (RFDN) e a mastigação da matéria seca (MMS) e da FDN (MFDN) em minutos por kg.

A eficiência de alimentação (EA), a eficiência de ruminação (ER), o número de bolos ruminais por dia (NBR), o tempo de mastigação por dia (TMT) e o número de mastigações merícicas por dia (NM/dia) foram obtidos segundo técnica descrita por Burger et al. (2000).

Os dados obtidos foram submetidos à análise de variância, utilizando-se o programa estatístico SAEG (Ribeiro Júnior, 2001) e as médias dos tratamentos foram comparadas pelo teste de Tukey ao nível de $5 \%$ de probabilidade. 
Tabela 2: Composição química dos alimentos volumosos e concentrados utilizados nas dietas experimentais

\begin{tabular}{lccccccc}
\hline Nutrientes* & MS & PB & FDN & FDA & EE & LIG & NDT \\
\hline Alimentos & \multicolumn{7}{c}{$\%$ Matéria Seca } \\
\hline Cana-de-açúcar & 24,14 & 3,20 & 58,41 & 31,88 & 6,05 & 1,61 & 54,04 \\
Silagem de sorgo & 27,94 & 10,82 & 78,11 & 41,56 & 5,25 & 6,47 & 58,67 \\
Silagem de girassol & 23,65 & 12,20 & 65,06 & 51,59 & 8,94 & 6,88 & 49,75 \\
Capim -Tanzânia & 21,54 & 10,70 & 76,45 & 49,34 & 5,97 & 3,60 & 55,86 \\
Fubá de milho & 87,64 & 8,50 & 11,61 & 4,13 & 4,01 & 1,10 & 85,65 \\
Farelo de soja & 88,74 & 46,00 & 14,83 & 9,42 & 1,57 & 2,29 & 81,04 \\
\hline
\end{tabular}

${ }^{*} \mathrm{MS}=$ matéria seca; $\mathrm{PB}=$ proteína bruta; $F D N$ = fibra em detergente neutro; FDA = fibra em detergente ácido; $\mathrm{EE}$ = extrato etéreo; LIG = lignina; NDT = nutrientes digestíveis totais estimado pelas equações do NRC (2001)

\section{Resultados e discussão}

O maior tempo de alimentação ocorreu para a dieta com pasto de capim-tanzânia $(P<0,05)$, enquanto as demais dietas foram semelhantes entre si (Tabela 3 ), o que pode ser justificado pelos maiores valores para o consumo de MS $(18,28 \mathrm{~kg} / \mathrm{dia})$ e FDN $(11,62 \mathrm{~kg} / \mathrm{dia})$ da dieta com capim-tanzânia. Estes resultados obtidos quanto ao tempo de alimentação estão de acordo com aqueles encontrados por Mendonça et al. (2004) que, ao avaliarem o comportamento ingestivo de vacas leiteiras submetidas a dietas à base de silagem de milho ou cana-deaçúcar, não encontraram diferença para os tempos médios despendidos com alimentação e ruminação para as diferentes dietas experimentais. Apesar do maior consumo de FDN com a dieta à base de silagem de sorgo $(10,64 \mathrm{~kg})$ em relação às dietas com cana $(5,82 \mathrm{~kg})$ e silagem de girassol $(4,65 \mathrm{~kg})$, a maior digestibilidade da FDN da dieta com silagem de sorgo $(45,85 \%)$ (Martins et al., 2011), permitiu uma maior eficiência de consumo, o que ajuda a explicar a semelhança dos resultados de tempo de alimentação dessas três dietas avaliadas.

Polli et al. (1995) analisaram o comportamento ingestivo de bovinos e bubalinos em confinamento, alimentados com silagem de milho ou cana-de-açúcar, e também não encontraram diferenças nos tempos despendidos com alimentação e ruminação. Tempos de pastejo mais próximos aos deste trabalho $(472,50)$ foram encontrados por Zanine et al. (2009), 561,6 minutos, avaliando o comportamento ingestivo de vacas Girolandas em pastejo de Brachiaria brizantha.

O menor tempo despendido para ruminação foi para a dieta com silagem de girassol $(P<0,05)$, que diferiu das outras dietas, as quais foram iguais estatisticamente (Tabela 3). Estes resultados comprovam os encontrados na avaliação da composição química da fibra da silagem de girassol, que apresentou concentração elevada quanto ao teor de fibra em detergente ácido e lignina (Tabela 2 ), além de baixa digestibilidade da fibra em detergente neutro $(26,56 \%)$, o que acarretou baixo consumo desta dieta $(13,11$ $\mathrm{kg} \mathrm{MS/dia)} \mathrm{em} \mathrm{relação} \mathrm{às} \mathrm{demais}(17,84,17,49$ e 18,28 kg MS/dia, para as dietas com cana, silagem de sorgo e pasto de capim-tanzânia, respectivamente), conforme apresentado por Martins et al. (2011).

Segundo Mendonça et al. (2004), o tempo despendido com ruminação é altamente correlacionado com o consumo de FDN em bovinos. Neste caso, esperava-se um maior tempo de ruminação para a dieta com silagem de sorgo e pasto de capim-tanzânia em relação à cana-de-açúcar devido ao maior teor de FDN na dieta. Porém, para Beauchemin e BuchananSmith (1989), não só o teor de FDN nas dietas altera o tempo gasto com ruminação, como também a qualidade da FDN, ou seja, sua degradabilidade ruminal. Como a digestibilidade da FDN da dieta com cana-de-açúcar foi menor, isto implicou maior tempo de ruminação.

Tabela 3: Tempo de alimentação (TA), tempo de ruminação (TR) e tem-po de ócio (TO), em minutos/dia; número de períodos de alimentação (NPA), de ruminação (NPR) e de ócio (NPO), em número/dia; duração dos períodos de alimentação (DPA), ruminação (DPR) e ócio (DPO), em minutos/período, de vacas mestiças em lactação alimentadas com diferentes volumosos, e coeficientes de variação $(\mathrm{CV})$

\begin{tabular}{lccccc}
\hline Parâmetros & Cana-de-açúcar & Silagem Sorgo & Silagem Girassol & Capim-Tanzânia & CV (\%) \\
\hline TA (minutos/dia) & $282,50 \mathrm{~b}$ & $330,00 \mathrm{~b}$ & $241,25 \mathrm{~b}$ & $472,50 \mathrm{a}$ & 19,34 \\
TR (minutos/dia) & $506,25 \mathrm{a}$ & $540,00 \mathrm{a}$ & $406,25 \mathrm{~b}$ & $483,75 \mathrm{a}$ & 10,44 \\
TO (minutos/dia) & $651,25 \mathrm{~b}$ & $570,00 \mathrm{c}$ & $792,50 \mathrm{a}$ & $483,75 \mathrm{c}$ & 13,54 \\
\hline NPA (n\%/dia) & $12,63 \mathrm{a}$ & $14,25 \mathrm{a}$ & $12,00 \mathrm{a}$ & $10,13 \mathrm{~b}$ & 19,34 \\
NPR (n\%dia) & $13,63 \mathrm{~b}$ & $17,88 \mathrm{a}$ & $13,75 \mathrm{~b}$ & $13,63 \mathrm{~b}$ & 11,87 \\
NPO (n\%/dia) & $21,13 \mathrm{a}$ & $23,13 \mathrm{a}$ & $23,50 \mathrm{a}$ & $18,00 \mathrm{~b}$ & 11,45 \\
\hline DPA (min/período) & $22,79 \mathrm{~b}$ & $23,98 \mathrm{~b}$ & $20,16 \mathrm{~b}$ & $47,83 \mathrm{a}$ & 26,52 \\
DPR (min/período) & $37,93 \mathrm{a}$ & $30,93 \mathrm{~b}$ & $30,73 \mathrm{~b}$ & $36,75 \mathrm{a}$ & 17,05 \\
DPO (min/período) & $31,40 \mathrm{a}$ & $24,79 \mathrm{~b}$ & $34,34 \mathrm{a}$ & $27,09 \mathrm{~b}$ & 18,13 \\
\hline
\end{tabular}

Médias com letras iguais, na linha, não diferem, pelo teste de Tukey ao nível de $5 \%$ de significância. 
Quanto ao tempo de ócio, as dietas com silagem de sorgo e pasto de capim-tanzânia apresentaram menores tempos, diferindo $(P<0,05)$ em relação às outras dietas. A dieta com canade-açúcar teve tempo de ócio intermediário e a com silagem de girassol foi a que apresentou o maior tempo de ócio.

Este resultado com a dieta à base de cana-de-açúcar se deve à baixa digestibilidade da fibra em detergente neutro $(27,86 \%$, Martins et al., 2011) que contribuiu para um maior enchimento físico do rúmen, além da maior proporção de concentrado nesta dieta (Tabela 1). Isso também ocorreu na dieta com silagem de girassol, onde a maior proporção de concentrado também pode ter colaborado para aumentar o tempo de ócio, pois o suprimento de energia torna-se mais rápido, além do baixo consumo de matéria seca e baixa digestibilidade da fibra em detergente neutro apresentados nessa dieta.

Gonçalves et al. (2001) trabalhando com cabras leiteiras alimentadas com diferentes relações volumoso:concentrado, verificaram que, com o aumento do nível de concentrado nas dietas, houve diminuição nos tempos despendidos com alimentação e ruminação e, em contrapartida, houve aumento no tempo despendido com ócio. Este fato foi confirmado por Burger et al. (2000) que, trabalhando com bezerros holandeses, constataram que os tempos médios gastos com alimentação e ruminação diminuíram linearmente com o aumento do nível de concentrado nas dietas, ao contrário do que ocorreu com o tempo de ócio, o qual aumentou linearmente.

O número de períodos de alimentação (NPA) (Tabela 3) foi menor na dieta com pasto de capim-tanzânia comparada com número maior de períodos de ócio em relação à dieta com pasto de capim-tanzânia $(P<0,05)$. Este resultado pode estar associado não apenas à dieta em si, como também ao próprio ambiente, visto que não houve diferença apenas para as vacas que receberam a alimentação no cocho.

Os dados de duração dos períodos de alimentação (DPA), ruminação (DPR) e de ócio (DPO), quando estes são relacionados com os demais dados da Tabela 3 , observa-se que a dieta com pasto de capim-tanzânia teve um maior tempo de alimentação, com menor número de refeições e maior duração dos períodos de refeição $(P<0,05)$, enquanto as demais dietas, em confinamento, apresentaram efeito contrário, sendo semelhantes entre si.

Quanto à duração do período de ruminação, as dietas com cana-de-açúcar e com pasto de capim-tanzânia foram superiores $(P<0,05)$ em relação à silagem de sorgo e de girassol $(P>0,05)$. A dieta com silagem de girassol apresentou um menor tempo de ruminação, assim como uma duração do período de ruminação inferior. As outras dietas, que apresentaram número de períodos de ruminação menor, foram compensadas com a maior duração do período de ruminação. Quanto à duração do período de ócio, este foi maior $(P<0,05)$ para as dietas com cana-de-açúcar e silagem de girassol e menor para as demais dietas avaliadas.

O tempo de mastigação merícica (TM/bolo), assim como o número de mastigação merícica por bolo (NM/bolo), foi menor na dieta com pasto de capim-tanzânia $(P<0,05)$ em relação às outras dietas que não diferiram entre si $(P>0,05)$. Este fato pode estar relacionado com a maior seletividade da dieta a pasto em relação às outras dietas em confinamento (Tabela 4).

Tabela 4: Tempo de mastigação por bolo (TM/bolo), número de mastigações por bolo (NM/bolo), número de mastigações por minuto $(\mathrm{NM} / \mathrm{min})$, número de mastigações por dia (NM/dia), número de bolos por dia (NB/dia), tempo total de mastigação (TTM), de vacas mestiças em lactação alimentadas com diferentes volumosos, e coeficientes de variação $(\mathrm{CV})$

\begin{tabular}{lccccc}
\hline \multicolumn{5}{c}{ Volumosos nas dietas } \\
\hline Parâmetros & Cana-de-açúcar & Silagem Sorgo & Silagem Girassol & Capim-Tanzânia & CV (\%) \\
\hline TM/bolo(seg) & $57,63 \mathrm{a}$ & $53,71 \mathrm{a}$ & $60,14 \mathrm{a}$ & $47,41 \mathrm{~b}$ & 12,77 \\
NM/bolo & $54,50 \mathrm{a}$ & $50,19 \mathrm{a}$ & $54,14 \mathrm{a}$ & $42,29 \mathrm{~b}$ & 14,84 \\
NM/minuto & $56,51 \mathrm{a}$ & $56,19 \mathrm{a}$ & $53,63 \mathrm{a}$ & $53,73 \mathrm{a}$ & 8,99 \\
NM/dia & $28.626,99 \mathrm{a}$ & $30.436,16 \mathrm{a}$ & $22.023,41 \mathrm{~b}$ & $26.046,34 \mathrm{ab}$ & 16,63 \\
NB/dia & $543,65 \mathrm{a}$ & $608,54 \mathrm{a}$ & $417,49 \mathrm{~b}$ & $616,58 \mathrm{a}$ & 13,37 \\
TTM( min) & $788,75 \mathrm{~b}$ & $870,00 \mathrm{a}$ & $647,50 \mathrm{c}$ & $956,25 \mathrm{a}$ & 10,36 \\
\hline
\end{tabular}

Médias com letras iguais, na linha, não diferem, pelo teste de Tukey ao nível de $5 \%$ de significância.

outras dietas que foram iguais $(P>0,05)$ entre si, o que pode ser justificado pela maior duração do período de alimentação nessa dieta.

Com relação ao número de períodos de ruminação (NPR), a dieta com silagem de sorgo foi maior $(P<0,05)$ em relação às demais, que foram semelhantes entre si $(P>0,05)$. Isto está relacionado com o maior teor de FDN (Tabela 1) desta dieta em relação às outras, conforme discutido anteriormente.

No que concerne ao número de períodos de ócio (NPO), as dietas com cana-de-açúcar, silagem de sorgo e silagem de girassol não diferiram $(P>0,05)$ entre si, as quais tiveram um
O número de mastigação merícica ( $\mathrm{NM} /$ minuto) não diferiu $(P>0,05)$ entre as dietas estudadas. Em relação ao número de mastigações merícicas por dia, a dieta com silagem de girassol foi semelhante à dieta com pasto de capim-tanzânia e inferior às demais. Já quanto ao número de bolos por dia e quanto ao tempo total de mastigação por dia, a dieta com silagem de girassol apresentou menor valor, em comparação às outras dietas.

O maior tempo total de mastigação (TTM) observado foi para a dieta com silagem de sorgo e pasto de capim-tanzânia $(P>0,05)$; a cana-de-açúcar ficou em situação intermediária quanto ao tempo total de mastigação em relação às outras dietas, e a 
dieta com silagem de girassol apresentou o menor tempo total de mastigação.

Resultados semelhantes foram encontrados por Mendonça et al. (2004) que, trabalhando com vacas em lactação alimentadas com cana-de-açúcar e silagem de milho, não encontraram diferença significativa quanto ao número de bolos ruminais por dia, 548 e 555, respectivamente.

O menor valor para o tempo total de mastigação na dieta com silagem de girassol pode ser explicado pelos menores tempos de alimentação e ruminação para esta dieta. De acordo com Van Soest (1994), a atividade de mastigação tem um importante papel no consumo e digestão de forragens, influenciando a taxa de secreção salivar, solubilizando os nutrientes, quebrando e reduzindo o tamanho das partículas e expondo os nutrientes, para a colonização e aumentando a taxa de passagem da digesta.

A dieta com pasto de capim-tanzânia diferiu $(P<0,05)$ das demais, apresentando um maior tempo para o consumo de matéria seca em min/kg, o que acarretou em menor eficiência da alimentação de matéria seca em $\mathrm{kg} \mathrm{MS/hora} \mathrm{em} \mathrm{relação} \mathrm{às}$ outras dietas, as quais não diferiram entre si (Tabela 5). explicar a maior perda de peso $(P<0,05)$, conforme apresentado por Martins et al. (2011).

Em experimento realizado por Palhano et al. (2007), observaramse valores para a taxa de ingestão que variaram de 7,5 a $17,0 \mathrm{~g}$ $\mathrm{MS} /$ minuto/animal entre a menor e a maior altura do dossel, e foram inferiores aos descritos por Rego et al. (2006), que reportaram valores de 19,0 a 38,0 g MS/minuto para novilhos em pastagem de capim-tanzânia, que foram semelhantes aos obtidos neste trabalho.

Apesar da dieta com silagem de girassol ter propiciado maior tempo em ócio e menor consumo de matéria seca, a eficiência da alimentação de matéria seca foi maior neste tratamento em relação à dieta com pasto de capim-tanzânia. Este resultado corrobora com a maior eficiência alimentar para dieta com silagem de girassol (1,36 kg leite/kg MS) e menor eficiência alimentar para a dieta com pasto de capim-tanzânia $(1,07 \mathrm{~kg}$ leite/kg MS), sendo importante ressaltar que a menor eficiência alimentar das vacas em pasto de capim-tanzânia pode estar relacionada com o maior gasto energético com as atividades de apreensão do alimento em condições de pastejo. Todavia, não houve diferença $(P>0,05)$ na produção de leite corrigida

Tabela 5: Tempo de consumo de matéria seca (CMS) em minutos/kg, consumo de fibra em detergente neutro (CFDN) em minutos/kg, ruminação da matéria seca (RMS) em minutos/kg, ruminação da fibra em detergente neutro (RFDN) em minutos $/ \mathrm{kg}$, mastigação da matéria seca (MMS) em minutos/kg, mastigação da fibra em detergente neutro (MFDN) em minuto/kg, eficiência de alimentação da matéria seca (EALMS), eficiência de alimentação da fibra em detergente neutro (EALFDN), eficiência de ruminação da MS (ERMS), eficiência de ruminação da FDN (ERFDN) de vacas mestiças em lactação alimentadas com diferentes volumosos, e coeficientes de variação (CV)

\begin{tabular}{llllll}
\hline \multicolumn{5}{c}{ Volumosos nas Dietas } \\
\hline Parâmetros & Cana-de-açúcar & Silagem Sorgo & Silagem Girassol & Capim-Tanzânia & CV (\%) \\
\hline CMS (min/kg) & $15,93 \mathrm{~b}$ & $19,09 \mathrm{~b}$ & $18,65 \mathrm{~b}$ & $26,93 \mathrm{a}$ & 24,82 \\
CFDN (min/kg) & $48,84 \mathrm{a}$ & $31,21 \mathrm{~b}$ & $56,86 \mathrm{a}$ & $43,43 \mathrm{a}$ & 32,71 \\
RMS (min/kg) & $28,64 \mathrm{a}$ & $31,40 \mathrm{a}$ & $31,79 \mathrm{a}$ & $26,90 \mathrm{a}$ & 13,88 \\
RFDN (min/kg) & $88,46 \mathrm{a}$ & $51,45 \mathrm{~b}$ & $101,03 \mathrm{a}$ & $42,83 \mathrm{~b}$ & 39,00 \\
MMS (min/kg) & $44,57 \mathrm{a}$ & $50,48 \mathrm{a}$ & $50,44 \mathrm{a}$ & $53,83 \mathrm{a}$ & 15,65 \\
MFDN (min/kg) & $137,30 \mathrm{a}$ & $82,67 \mathrm{~b}$ & $157,89 \mathrm{a}$ & $86,26 \mathrm{~b}$ & 34,28 \\
EALMS (kgMS/hora) & $3,97 \mathrm{a}$ & $3,27 \mathrm{a}$ & $3,34 \mathrm{a}$ & $2,49 \mathrm{~b}$ & 24,47 \\
EALFDN(kgFDN/hora) & $1,28 \mathrm{~b}$ & $1,99 \mathrm{a}$ & $1,17 \mathrm{~b}$ & $1,60 \mathrm{a}$ & 30,71 \\
ERMS (kgMS/hora) & $2,13 \mathrm{a}$ & $1,94 \mathrm{~b}$ & $1,93 \mathrm{~b}$ & $2,26 \mathrm{a}$ & 12,76 \\
ERFDN (kgFDN/hora) & $0,70 \mathrm{c}$ & $1,18 \mathrm{~b}$ & $0,68 \mathrm{c}$ & $1,43 \mathrm{a}$ & 17,29 \\
\hline
\end{tabular}

Médias com letras iguais, na linha, não diferem, pelo teste de Tukey ao nível de 5\% de significância.

Para Albright (1994), o tempo gasto com alimentação é um dos fatores limitantes do consumo de forragem, em função do número de movimentos mastigatórios. Em condição de pastejo, o consumo está em função de variáveis associadas ao comportamento do animal que, segundo uma visão mecanística, é descrito através do tempo de pastejo, taxa de bocados e tamanho de bocados. Neste trabalho, pode-se dizer que houve um menor consumo de nutrientes por unidade de tempo para a dieta com pasto de capim-tanzânia, o que pode ter implicado um maior gasto de energia com esta atividade. Isto ajuda a para $4 \%$ de gordura $(19,12 \mathrm{~kg} / \mathrm{dia})$ entre as dietas avaliadas, conforme Martins et al. (2011). Desta forma, as diferenças verificadas no comportamento ingestivo para as diferentes dietas não implicaram variação na produção de leite das vacas, possivelmente, em função de ajustes no comportamento, associados ao consumo e qualidade das dietas experimentais. O tempo gasto para a ruminação e mastigação da FDN foi maior $(P<0,05)$ para as dietas com cana-de-açúcar e silagem de girassol, o que pode estar relacionado com as características de baixa digestibilidade da fibra destes volumosos aliadas à 
elevada proporção de concentrado nestas dietas, que pode ter afetado a degradação da fibra.

A eficiência de alimentação da FDN foi maior $(P<0,05)$ para as dietas com silagem de sorgo e pasto de capim-tanzânia, as quais proporcionaram um maior consumo de FDN por hora em relação à dieta com cana-de-açúcar e silagem de girassol que apresentaram similaridade quanto ao consumo de FDN. Este resultado também está de acordo com a maior digestibilidade da FDN para as dietas com silagem de sorgo (45,88\%) e pasto de capim-tanzânia $(45,70 \%)$, em relação às dietas a base de cana $(27,86 \%)$ e silagem de girassol $(26,56 \%)(P<0,05)$.

O tempo de ruminação da matéria seca não diferiu entre as dietas $(P>0,05)$; todavia, a eficiência de ruminação da matéria seca foi maior $(P<0,05)$ para as dietas com cana-de-açúcar e pasto com capim-tanzânia. A eficiência de ruminação da FDN foi maior $(P<0,05)$ para a dieta com pasto de capim-tanzânia. Esta dieta proporcionou ruminação de uma maior quantidade de fibra em detergente neutro por hora. As dietas com silagem de girassol e com cana-de-açúcar foram as que apresentaram menores eficiências de ruminação da FDN e não diferiram entre si $(P>0,05)$. A dieta com silagem de sorgo foi intermediária quanto à eficiência de ruminação da FDN. Estes resultados se devem à maior proporção de concentrado nas dietas com silagens de cana e de girassol.

De acordo com os resultados relatados por Mendonça et al. (2004), a eficiência de ruminação da matéria seca se eleva quando o nível de concentrado da dieta é aumentado. Este fato foi verificado também por Burger et al. (2000), em que a eficiência de ruminação da matéria seca aumentou, linearmente, com a inclusão de concentrado nas dietas, enquanto a eficiência de ruminação da FDN decresceu linearmente. Segundo esses autores, isso ocorre, provavelmente, em virtude do declínio na atividade celulolítica dos micro-organismos ruminais, além de uma parte do concentrado ser regurgitada no bolo durante a ruminação.

\section{Conclusões}

As dietas com pasto de capim-tanzânia e silagem de sorgo proporcionam um maior tempo de alimentação e mastigação e maior eficiência de alimentação da fibra em detergente neutro.

As dietas com silagem de girassol e cana-de-açúcar propiciam maior eficiência de alimentação da matéria seca e menor eficiência da alimentação e ruminação da fibra em detergente neutro.

\section{Agradecimentos}

Ao Banco do Nordeste, pelo apoio financeiro, e à FAPEMIG e ao CNPq pelo auxílio com bolsas.

\section{Referências}

ALBRIGHT, J. L. Feeding behavior of dairy cattle. Journal of Dairy Science, Champaign, v. 76, n. 2, p. 485-498, 1994.

ASSOCIATION OF ANALITICAL CHEMIST-OAC. 1990. Official methods of analysis. 15. ed. Arlington: Virginia. $117 \mathrm{p}$.

BARROS, R.C.; ROCHA JÚNIOR, V.R.; SARAIVA, E.P.; MENDES, G.A.; MENEZES, G.C.C.; OLIVEIRA, C.R. de; ROCHA, W.J.B.; AGUIAR, A.C.R.; SANTOS, C.C.R. Comportamento ingestivo de bovinos Nelore confinados com diferentes níveis de substituição de silagem de sorgo por cana-de-açúcar ou bagaço de cana amonizado com ureia. Revista Brasileira de Ciência Veterinária, v. 18, n. 1, p. 6-13, 2011.

BEAUCHEMIN, K. A.; BUCHANAN-SMITH, J. G. Effects of neutral detergent fiber concentration and supplementary long hay on chewing activities and milk production of dairy cows. Journal of Dairy Science, Champaign, v. 72, n. 9, p. 2288-2300, 1989.

BURGER, P. J.; PEREIRA, J.C.; QUEIROZ, A.C.; SILVA, J.F.C.; VALADARES FILHO, S.C.; CECON, P.R.; CASALI, A.D.P. Comportamento ingestivo em bezerros holandeses alimentados com dietas contendo diferentes níveis de concentrado. Revista Brasileira de Zootecnia, Viçosa, v. 29, n. 1, p. 236-242, 2000.

CARVALHO, G.G.P.; GARCIA, R.; PIRES, A.J.V.; AZEVÊDO J.A.G.; FERNANDES, F.É. Comportamento ingestivo de cabras leiteiras alimentadas com farelo de cacau ou torta de dendê. Pesquisa Agropecuária Brasileira, Brasília, v. 39, n. 9, p. 919-925, 2004.

CARVALHO, G.G.P.; PIRES, A.J.V.; SILVA, R.R.; RIBEIRO, L.S.O.; CHAGAS, D.M.T. Comportamento ingestivo de ovinos Santa Inês alimentados com dietas contendo farelo de cacau. Revista Brasileira de Zootecnia, Viçosa, v. 37, n. 4, p. 660-665, 2008.
CASALI, A.O., DETMANN, E., VALADARES FILHO, S.C., PEREIRA, J.C., HENRIQUES, L.T., FREITAS, S.G. de, PAULINO, M.F. Influência do tempo de incubação e do tamanho de partículas sobre os teores de compostos indigestíveis em alimentos e fezes bovinas obtidos por procedimentos in situ. Revista Brasileira de Zootecnia, Viçosa, v. 37, n. 2, p. 335-342, 2008.

COCHRAN, R.C.; ADAMS, D.C.; WALLACE, J.D. Predicting digestibility of different diets whith internal markers: evaluation of four potential markers. Journal of Animal Science, v. 63, n. 5, p. 1476-1483, 1986.

DETMANN, E., PAULINO, M.F., ZERVOUDAKIS, J.T., VALADARES FILHO, S.C., EUCLYDES, R.F., LANA, R.P., QUEIROZ, D.S. Cromo e indicadores internos na determinação do consumo de novilhos mestiços, suplementados, a pasto. Revista Brasileira de Zootecnia, Viçosa, v. 30, n. 5, p. 1600-1609, 2001

GARDNER, A. L. Técnicas de pesquisa em pastagens e aplicabilidade de resultados em sistemas de produção. Brasília, DF. IICA. EMBRAPA/CNPGL. 1986. 197 p.

GONÇALVES, A.L.; LANA, R.P.; RODRIGUES, M.T.; VIEIRA, R.A.M.; QUEIROZ, A.C.; HENRIQUE, D.S. Padrão Nictemeral do $\mathrm{pH}$ Ruminal e Comportamento Alimentar de Cabras Leiteiras Alimentadas com Dietas Contendo Diferentes Relações Volumoso: Concentrado. Revista Brasileira de Zootecnia, Viçosa, v. 30, n. 6, p. 1886-1892, 2001.

INFORME AGROPECUÁRIO. Caatinga. Belo Horizonte: EPAMIG, v. 17, n. 81, 1994.

JOHNSON, A.D. Sample preparation and chemical analysis of vegetation. In: t'MANNETJE, L. (Ed.). Measurement of grassland vegetation and animal production. Aberystwyth: Commonwealth Agricultural Bureaux, 1978, p. 96-102. 
MARTINS, S.C.S.G.; ROCHA JÚNIOR, V.R.; CALDEIRA, L.A.; PIRES, D.A.A.P.; BARROS, I.C.; SALES, E.C.J.; SANTOS, C.C.R.; AGUIAR, A.C.R.; OLIVERIA, C.R. Consumo, digestibilidade, produção de leite e análise econômica de dietas com diferentes volumosos. Revista Brasileira de Saúde e Produção Animal, v. 12, n. 3, p. 691-708, 2011.

MENDONÇA, S. de S.; CAMPOS, J.M. de S.; FILHO, S. de C.V.; VALADARES, R. F. D.; SOARES C.A.; LANA, R. de P.; QUEIROZ, A.C. de; ASSIS, A.J. de; PEREIRA, M.L.A. Comportamento Ingestivo de Vacas Leiteiras Alimentadas com Dietas à Base de Cana-de-Açúcar ou Silagem de Milho. Revista Brasileira de Zootecnia, v. 33, n. 3, p. 723-728, 2004.

MOTT, G.O., LUCAS, H.L. The design, conduct and interptretation of grazing trials on cultivated and improved pastures. In: INTERNATIONAL GRASSLAND CONGRESS, 6., 1952, Pensylvania. Proceedings... Pensylvania: State College Press, 1952, p. 1380-1385.

NATIONAL RESEARCH COUNCIL. Nutrient requirements of dairy cattle. 7. ed. Washington: National Academy, 2001, 381 p.

OLIVEIRA, P.A.; MARQUES, J.A.; BARBOSA, L.P.; OLIVEIRA, G.J.C.; PEDREIRA, T.M.; SILVA, L.L. Aspectos metodológicos do comportamento ingestivo de vacas lactantes em pastejo de Brachiaria decumbens. Revista Brasileira de Saúde e Produção Animal, v. 12, n. 1, p. 166-175, 2011.

OLIVO, C.J.; ZIECH, M.F.; MEINERZ, G.R., BOTH, J. F.; AGNOLIN, C.A.; VENDRAME, T. Comportamento ingestivo de vacas em lactação em diferentes sistemas forrageiros. Revista Brasileira de Zootecnia, v. 37, n. 11, p. 2017-2023, 2008.

PALHANO, A.L.; FACCIO, P.C. de; DUTTRUCH, C.J.R.; MORAES, A. de; SILVA, S.C.da; MONTEIRO, A.L.G. Características do processo de ingestão de forragem por novilhas holandesas em pastagens de capim-mombaça. Revista Brasileira de Zootecnia, v. 36, n. 4, p. 1014-1021, 2007.

PEREIRA, J.C.; CUNHA, D.N.F.V.; CECON, P.R.; FARIAS, E.S. Comportamento ingestivo e taxa de passagem de partículas em novilhas leiteiras de diferentes grupos genéticos submetidas a dietas com diferentes níveis de fibra. Revista Brasileira de Zootecnia, Viçosa, v. 36, n. 6, p. 2134-2142, 2007.

PHILLIPS, C. J.; RIND, M. I. The effects of social dominance on the production and behavior of grazing dairy cows offered forage supplements. Journal of Dairy Science, Champaign, v. 85, n. 1, p. 51-59, 2001.
POLLI, V. A.; RESTLE, J.; SENNA, D. B. Comportamento de bovinos e bubalinos em regime de confinamento: I atividades. Ciência Rural, Santa Maria, v. 25, p. 127-131, 1995.

REGO, F.C.A; DAMASCENO, J.C.; FUKUMOTO, N.M.; CÔRTES, C.; HOESHI, LAURI; MARTINS, E.N.; CECATO, U. Comportamento ingestivo de novilhos mestiços em pastagens tropicais manejadas em diferentes alturas. Revista Brasileira de Zootecnia, v. 35, n. 4, p. 1611-1620, 2006 (supl.).

RIBEIRO JÚNIOR, J.I. SAEG Sistema para análises estatísticas e genética, versão 8.0. Viçosa: Fundação Arthur Bernardes, 2001, $301 \mathrm{p}$.

SANTOS, F.A.P.; CARMO, C.A.; MARTINEZ, J.C.; PIRES, A.V.; BITTAR, C.M.M. Desempenho de vacas em lactação recebendo dietas com diferentes teores de amido total, acrescidas ou não de levedura (Saccharomyces cerevisiae). Revista Brasileira de Zootecnia, v. 35, n. 4, p.1568-1575, 2006.

SNIFFEN, C. J., CONNOR, J. D.; VAN SOEST, P. J.; FOX, D.G.; RUSSELL, J.B. A net carbohydrate and protein system for evaluating cattle diets: II Carbohydrate and protein availability. Journal of Dairy Science, v. 70, n. 11, p. 3562-3577, 1992.

SOUSA, D. de P.; CAMPOS, J.M. de S.; VALADARES FILHO, S. de C.; LANA, R. de P.; SEDIYAMA, C.A.Z.; NETO, J.M. Comportamento ingestivo, consumo e digestibilidade de nutrientes, produção e composição do leite de vacas alimentadas com silagem de milho ou cana-de-açúcar com caroço de algodão. Revista Brasileira de Zootecnia, v. 38, n. 10, p. 2053-2062, 2009.

VAN SOEST, P. J. Nutritional ecology of the ruminant. 2. ed. Ithaca: Cornell, 1994. 476 p.

VAN SOEST, J. P.; ROBERTSON, J. B.; LEWIS, B. A. Methods for dietary fiber, neutral detergent fiber, and nonstarch polysaccharides in relation to animal nutrition. Journal of Animal Science, Champaign, v. 74, n. 10. p. 3583-3597, 1991.

ZANINE, A.M.; VIEIRA, B.R.; FERREIRA, D.J.; VIEIRA, A.J.M.; LANA, R.P.; CECON, P.R. Comportamento ingestivo de vacas Girolandas em pastejo de Brachiaria brizantha e Coast-cross. Revista Brasileira de Saúde e Produção Animal, v. 10, n. 1, p. 8595, 2009. 